\title{
TENSÕES INTERNAS NA TEORIA DOS DIREITOS DE NOZICK
}

\author{
Aluirio Couto
}

\author{
Universidade Federal de Minas Gerais
}

\begin{abstract}
Resumo: Desde que Nozick publicou, em 1974, o clássico Anarquia, Estado e Utopia (doravante AEU), muita tinta tem sido gasta na tarefa de discutir o que ficou conhecido como Teoria da Titularidade. Em linhas gerais, essa teoria busca estabelecer as condições de apropriação inicial, transferência e retificação de propriedade. Os filósofos ficaram especialmente interessados nas implicações antiredistributivistas da argumentação de Nozick. Menos atenção, contudo, é dada à estrutura prévia de direitos individuais que Nozick ofereceu na primeira parte do livro. Será que ela pode ser plausivelmente defendida? Neste artigo, defendo que ela sofre de tensões internas que a tornam uma base frágil para 0 projeto nozickiano.
\end{abstract}

Palavras-chave: Nozick, Direitos, Autopropriedade.

Abstract: Since the publication of Nozick's 1974 classic Anarchy, State, and Utopia (henceforth AEU), a lot of ink has been spent in the discussion of what came to be known as Entitlement Theory. In general lines, this theory tries to establish the conditions of initial acquisition, transfer, and rectification of property. Philosophers manifested special interest in the anti-redistributivist implications of the theory. Less attention, however, is given to the previous structure of individual rights offered by Nozick in the first part of his book. Can it be plausibly defended? In this paper, I advocate that it suffers from internal tensions that render it a fragile basis for the nozickian project.

Keywords: Nozick, Rights, Self-ownership.

\section{Introdução}

Nozick é tido como um dos grandes nomes do libertarismo. Embora a marca distintiva das teorias libertárias seja a grande importância atribuída à liberdade individual, é preciso oferecer-lhe os devidos fundamentos. Por que devemos supor que as pessoas têm, por exemplo, liberdades econômicas ou a liberdade de se associar com quem quiserem? Filósofos como Nozick defendem que as pessoas têm direitos. De fato, o primeiro trecho de AEU mostra claramente a força das pretensões de Nozick:

Os indivíduos têm direitos e há coisas que nenhuma pessoa ou grupo lhes pode fazer (sem violar seus direitos). Estes direitos são de tal maneira fortes e de grande alcance que levantam a questão do que o estado e seus mandatários podem fazer, se é que podem fazer alguma coisa. Que espaço deixam os direitos individuais ao estado? (2009 [1974], p.21) 
Mas como ele defende tal coisa? Esses direitos são básicos ou se assentam em outros fundamentos? E quais são suas implicações? Muitas perguntas podem ser feitas a respeito da marcante abertura de AEU. A pergunta que me interessa neste artigo diz respeito aos aspectos internos da própria teoria de Nozick. Será que ele pode sustentar tudo o que ele sustenta ao mesmo tempo? Pretendo argumentar que não. Para motivar tese de que a teoria de Nozick apresenta tensões internas de difícil solução, apresento antes os aspectos básicos de sua teoria e algumas objeções que o forçam a modificála. É a partir dessas modificações que ficará claro o que entendo por "tensões internas" e porquê elas emergem.

\section{Direitos individuais}

Wolff (1991, p.19-23) apresenta os aspectos básicos dos direitos individuais nozickianos: 1) são direitos negativos de não-interferência na vida, liberdade e propriedade individuais ${ }^{1}$; 2) impõem restrições ao que se pode fazer aos outros e 3) a respeito do que se pode fazer valer, são exaustivos ${ }^{2}$.

Para entender o que são direitos negativos, é útil vê-los em contraste com os direitos positivos. $\mathrm{O}$ direito positivo de um indivíduo $\mathrm{A}$ ao bem $\mathrm{x}$ impõe a pelo menos um $\mathrm{B}$ o dever de fornecer $\mathrm{x}$ a $\mathrm{A}$. Se $\mathrm{A}$ tem o direito positivo a uma moradia decente, algum B terá de provê-lo de uma moradia decente. A ideia de direito positivo não especifica quem ou o que deve ser esse B. Pode ser um indivíduo, um conjunto deles ou até mesmo uma instituição. Os direitos negativos, por sua vez, têm outra estrutura. Se A tem o direito negativo à vida, isso não quer dizer que pelo menos um $\mathrm{B}$ deve fornecer a ele condições de se manter vivo. $\mathrm{O}$ direito negativo à vida implica que quaisquer indivíduos, conjuntos deles ou instituições têm o dever de não tirar a vida de A. Os direitos negativos impõem deveres de não-interferência.

Nozick pensa que os direitos individuais limitam o que se pode fazer às pessoas. Estas, pensa ele, são invioláveis e dotadas de direitos absolutos ${ }^{3}$. Nozick dá o nome de "restrições secundárias" (side constraints, no original) a essas barreiras morais que protegem as pessoas das ações de terceiros. A perspectiva nozickiana de inviolabilidade não é nova: “[a]s restrições secundárias à ação refletem o princípio kantiano subjacente de que os

1 Os direitos individuais são direitos naturais. Nozick segue a tradição de Locke (2001 [1690]), para quem os direitos antecedem qualquer reconhecimento institucional.

2 A expressão desajeitada "fazer valer" é uma tentativa aproximada de traduzir o original to enforce.

${ }^{3}$ Isso não quer dizer que as pessoas são intocáveis em todos os contextos. Muitas vezes, elas violam direitos de terceiros. Nesses casos, Nozick certamente admitiria a existência de mecanismos institucionais de punição. Ver, por exemplo, o capítulo 5 de AEU. 
indivíduos são fins e não meros meios; não podem ser sacrificados ou usados na obtenção de outros fins sem o seu consentimento" (2009 [1974], p.62).

Pode-se responder com o argumento de que instrumentalizar alguém é errado quando os fins são espúrios. Por exemplo, se decido fingir que sou amigo de um colega de trabalho porque, além de rico, ele é perdulário quando sai para se divertir com as pessoas, trato-o como um instrumento para promover meu ganho pessoal. Isso é bem diferente, prossegue a resposta, de instrumentalizar os outros para fins nobres, como a diminuição da pobreza. Logo, seria moralmente correto confiscar parte da propriedade dos mais ricos para subsidiar os mais pobres. Nozick rejeitaria a objeção, pois seu proponente não percebe que o problema de instrumentalizar as pessoas é o próprio ato de instrumentalizá-las. As boas consequências do ato de usar uns em prol de outros não enfraquecem os direitos individuais. Isso inclui até mesmo casos em que uma violação do direito à vida impediria a violação subsequente de vários direitos do mesmo tipo. Em termos mais abstratos, Eric Mack formula a ideia do seguinte modo:

Tal como Nozick entende esse direito [o direito à vida], ele proíbe que $\mathrm{A}$ (sem ser provocado) mate $\mathrm{B}$ mesmo se $\mathrm{A}$ puder impedir $\mathrm{W}$ de matar $\mathrm{X}, \mathrm{Y}$ e $\mathrm{Z}$ matando apenas B. Embora em certo sentido possa parecer menos mal que B seja morto do que $\mathrm{X}, \mathrm{Y}$, e Z, A permanece obrigado a não matar B. Por meio do assassinato de $\mathrm{B}$, A não pode impedir o mal que $\mathrm{W}$ irá praticar ao matar X, Y e Z. (2014, p. 7, grifo do autor).

Por fim, o último aspecto básico dos direitos individuais é o seguinte: a respeito do que se pode fazer valer, eles são exaustivos. Em termos mais simples, a ideia em causa é a de que somente a garantia dos direitos individuais justifica o uso de medidas como coerção e punição. Assumamos que tenho direito à integridade física e à propriedade privada. Se vivo em uma sociedade regida pelo estado, tenho a prerrogativa de exigir que seus oficiais garantam, se necessário com o uso da força, o respeito a meus direitos. Se, por outro lado, sou demasiadamente pobre e desejo que me forneçam condições mais razoáveis de vida, o estado não pode coagir alguém a me satisfazer. Ninguém pode ser forçado a me servir, uma vez que ninguém pode ser instrumentalizado em prol de terceiros. Logo, quando dizemos que os direitos exaurem o que se pode fazer valer, o que realmente dizemos é que os direitos negativos exaurem o que se pode fazer valer.

\section{Autopropriedade}

De modo um tanto impreciso, a tese da autopropriedade diz que cada um é moralmente proprietário de si mesmo. O termo "propriedade" deve ser entendido em sua acepção mais comum: do mesmo modo em que sou dono 
do computador que está em minha frente, as pessoas são donas de si. O conceito de autopropriedade não é idêntico à tese da autopropriedade. $\mathrm{O}$ primeiro apenas expressa a ideia de pertencimento a si mesmo. Ele não é verdadeiro ou falso, embora possa ser incoerente ou demasiadamente vago. A segunda estabelece que efetivamente somos donos de nós mesmos (COHEN, 1995). Uma vez que ser proprietário de algo implica um dado conjunto de direitos de propriedade, a tese da autopropriedade é normativa. E a exemplo das teses normativas, ou é verdadeira ou é falsa. É verdadeira caso tenhamos os direitos em causa e falsa caso não os tenhamos. Pode-se aceitar que o conceito de autopropriedade é coerente e ao mesmo tempo rejeitar a tese caso se descubra que é falsa. Mas é também possível rejeitar o conceito logo de saída. Kant, por exemplo, defendeu que só coisas podem ser apropriadas (1997 [1756]). Uma vez que pessoas não são coisas, não podem ser autoproprietárias. Caso ele esteja certo, o conceito não é coerente e o problema da verdade ou falsidade da tese correspondente sequer aparece. Vamos assumir, no entanto, que ela é coerente. A apresentação algo imprecisa que ofereci da tese não diz muito. É preciso torná-la mais rigorosa. Segundo a tese da autopropriedade,

cada agente, ao menos inicialmente (e.g., anteriormente a qualquer malfeito ou
acordo contratual), é, do ponto de vista moral, integralmente dono de si próprio.
A ideia básica da autopropriedade integral é a de ter sobre si mesmo todos os
direitos que o proprietário de um objeto inanimado (e.g., um carro) tem sobre
ele de acordo com a concepção mais robusta de propriedade privada sobre
objetos inanimados (VALLENTYNE, 2009, p.138).

Mas que direitos temos quando somos integralmente proprietários de algo? Vallentyne e van der Fossen (2014, p.2) listam os candidatos óbvios: 1) o direito ao controle do objeto do qual se é proprietário, o que inclui a reivindicação do direito de excluir terceiros do controle ${ }^{4}$; 2) o direito à compensação caso ele seja usado sem o consentimento do proprietário; 3) o direito de restringir previamente a ação de um agressor; 4) o direito de transferir esses direitos a outros por meio de ações como venda e doação e 5) a imunidade contra a perda não consentida desses direitos. Ser proprietário de algo, portanto, é ter um agregado de direitos sobre a propriedade. Na definição rigorosa que citei, as expressões "integral" e "mais robusta" indicam três coisas: a) que a concepção de propriedade em causa se refere ao conjunto logicamente mais forte de direitos de propriedade sobre algo, b) que eles são absolutos e c) que tais direitos têm apenas um titular. Suponha que sou o dono

${ }^{4}$ Em inglês, o termo que corresponde a "reivindicação de direito" é claim-right. Um indivíduo A tem uma reivindicação de direito a um indivíduo $B$ relativa a uma ação $X$ se e só se $B$ tem o dever para com $A$ de fazer $X$. No caso, a reivindicação é relativa a abster-se de assumir o controle da propriedade. 
do carro mencionado por Vallentyne. Um defensor da tese da autopropriedade pensa que os indivíduos têm sobre si o mesmo conjunto maximal e exclusivo de direitos absolutos que tenho sobre ele.

Vale a pena enfatizar algo que talvez não tenha ficado claro: como vimos, os direitos de propriedade não especificam limites ao que uma pessoa pode fazer com o que é dela. Assim, se sou o único proprietário do meu computador, posso destruí-lo quando quiser. $\mathrm{O}$ mesmo, porém, vale quando a propriedade é idêntica ao proprietário. Em Justice: What's the Right Thing to Do? (2008), Michael Sandel conta a história de um homem que consentiu em ser devorado por outro homem. Tratava-se literalmente de canibalismo consentido. A tese da autopropriedade é forte o suficiente para atribuir ao homem que se ofereceu como refeição o direito de ser destruído em uma prática que a maioria de nós certamente considera doentia.

\section{A separação das pessoas}

A principal motivação em favor da ideia de que as pessoas são as únicas proprietárias de si mesmas é o fato de que elas têm vidas separadas. Cada pessoa tem a sua e apenas a sua vida para viver. O contexto em que Nozick menciona a ideia de separação das pessoas é sua crítica ao utilitarismo:

Individualmente, cada um de nós escolhe por vezes sofrer alguma dor ou
sacrifício em prol de um benefício maior ou para evitar um mal maior [...]. Por
que não defender, de igual modo, que algumas pessoas têm de suportar alguns
custos que beneficiam mais outras pessoas, em nome do bem social geral? Mas
não há qualquer entidade social com um bem que sofra algum sacrifício em
proveito próprio. Há apenas pessoas individuais, pessoas individuais diferentes,
com as suas vidas individuais. Usar uma destas pessoas em benefício de outras é
usar essa pessoa e beneficiar outras. Nada mais. [...]. Usar uma pessoa deste
modo não respeita ou toma suficientemente em consideração o fato de ser uma
pessoa distinta, que a sua vida é a única vida que tem (2009 [1974], p.64).

Há uma diferença moral, pensa Nozick, entre um indivíduo decidir se submeter a algum custo para que ele próprio se beneficie no futuro e ver-se submetido a algum custo em prol do bem de uma entidade social. No primeiro caso, trata-se simplesmente de uma decisão individual acerca da distribuição temporal de custos e benefícios em uma mesma vida. No segundo, trata-se de tomá-lo como um instrumento em prol dos outros. A proposta de Nozick impede esse tipo de coisa. A ideia de separação das pessoas busca refletir a singularidade de cada vida individual, vida que de modo nenhum pode ser 
instrumentalizada a serviço de qualquer entidade. ${ }^{5}$ Indivíduos, por assim dizer, são únicos e distinguíveis. Uma vez que há apenas "pessoas individuais, pessoas individuais diferentes", é fácil perceber que uma tese que atribua a elas a propriedade de si mesmas e derive daí direitos individuais robustos reflete a singularidade de cada vida humana.

Eu disse acima que as restrições secundárias refletem a ideia kantiana de que pessoas não são meios, mas fins. A passagem reproduzida acima deixa claro que a motivação deontológica da posição de Nozick é a oposição ao que ele via como consequências indesejáveis do utilitarismo. Filósofos como Nozick consideram o utilitarismo uma teoria coletivista, cujo foco é o agregado total de utilidade em uma dada situação, e portanto incapaz de enxergar fronteiras entre as pessoas. Vale dizer que ninguém está propondo que as pessoas vivam isoladas umas das outras em ilhas de individualismo e egoísmo. A separação das pessoas apenas demarca o espaço dentro do qual o indivíduo é soberano.

\section{Vantagens}

David Sobel (2013) nota corretamente que a proteção fornecida pela tese da autopropriedade não está sujeita às contingências empíricas que os utilitaristas levam em conta. Como ele diz, "o fato de alguma coisa ser minha [...] fornece uma justificativa óbvia e muito mais confiável para a autoridade que tenho a respeito do que pode ocorrer com o que me pertence, por mais que outros indivíduos possam gerar um bem maior com o que é meu" (2013, p. 2). Outra vantagem da tese é sua proibição à coerção externa quando praticamos ações que só dizem respeito a nós mesmos. Sobel dá o nome de "liberdades millianas" a essas ações. A referência, claro, é a John Stuart Mill. No clássico On Liberty (1859), Mill defende que só podemos impedir um indivíduo de fazer algo que ele quer se isso for necessário para proteger as outras pessoas. Ausente o risco a terceiros, "[s]obre si próprio, sobre seu corpo e sua mente, o indivíduo é soberano" (2008 [1859], p.14). Uma vez que o acordo do caso contado por Sandel dizia respeito apenas aos indivíduos que voluntariamente consentiram com seus termos, não cabe a ninguém interferir. Sobre a destruição do próprio corpo, o indivíduo também é soberano. Evidentemente, a tese da autopropriedade seria pouco atrativa caso protegesse apenas os direitos de quem quer ser devorado pelos outros. Mas ela também protege coisas que valorizamos. Michael Otsuka (2003) observa que as

${ }^{5}$ Mack (2014, p.5) observa que utilitaristas não precisam defender a existência de entidades sociais. A agregação da utilidade não depende de tal coisa. 
consequências anti-paternalistas e anti-moralistas da tese da autopropriedade soam interessantes àqueles que apoiam as conclusões de Mill. A tese é maximamente garantista quando estão em causa temas como liberdade de expressão, eutanásia, relações sexuais consensuais entre capazes, uso de drogas, etc.

Mill era um grande entusiasta das liberdades individuais e foi talvez o maior representante da tradição liberal. Mas ele era um utilitarista. E como tal, justificava essas liberdades a partir da felicidade agregada que elas supostamente geram. As consequências da liberdade, diria Mill, são melhores do que as consequências do cerceamento dela. Mas e se não fossem? Propostas como a de Nozick fornecem uma base mais robusta para as liberdades millianas. Se as consequências de uma violação de direitos individuais gerarem mais felicidade, tanto pior para as consequências. Afinal, os direitos não são o tipo de coisa que colocamos sobre uma balança. Direitos são barreiras e essas barreiras restringem o que os outros podem fazer.

Será que isso é tudo? De fato, podemos aceitar que as pessoas devem ser tratadas como fins e a correspondente proibição de instrumentalizá-las. Mas, afinal, o que há de tão especial em uma pessoa? Como dar mais substância à ideia da singularidade de cada um? A resposta é a seguinte: uma pessoa é dotada de racionalidade, livre arbítrio, agência moral e da "habilidade de regular e guiar sua vida de acordo com uma concepção geral que escolhe aceitar” (NOZICK, 2009 [1974], p.82). Uma pessoa, portanto, é um ser

capaz de formular planos a longo prazo para a sua vida, de considerar e decidir
com base em princípios abstratos ou considerações que formula para si próprio,
e portanto não um brinquedo dos estímulos imediatos, um ser que limita o seu
próprio comportamento de acordo com alguns princípios ou uma imagem que
tem do que uma vida apropriada é para si mesmo e para os outros, etc. [...].
Moldar a sua vida segundo um plano geral é a maneira que dada pessoa tem de
dar sentido à sua vida; só um ser com a capacidade de moldar a sua vida pode
ter ou esforçar-se por ter uma vida com sentido (2009 [1974], p.82-3).

Gostamos de nos ver assim. Queremos moldar a nossa vida segundo planos que nós mesmos fazemos. O que a tese da autopropriedade oferece, aparentemente, é precisamente uma espécie de "espaço moral" amplo o suficiente para moldarmos a nossa vida do jeito que quisermos. Se as pessoas não podem ser usadas como instrumentos em prol de fins alheios, é razoável pensar que elas têm o controle exclusivo de suas vidas. A tese da autopropriedade, portanto, não é apenas compatível com a perspectiva de vida com sentido proposta por Nozick, mas parece ajustar-se bem a ela. 


\section{O problema da conflação}

A tese da autopropriedade é extremamente exigente. A proteção que ela dá às pessoas contra o uso ou agressão por parte de terceiros é absoluta. Esse caráter absolutista tem a vantagem adicional de dar à tese um contorno preciso, dado que é geralmente muito difícil admitir exceções a teses filosóficas sem correr o risco de descaracterizá-las. Tal como está, a tese é simples e surpreendentemente clara. Embora reconheça suas vantagens, Sobel oferecelhe o que talvez sejam as melhores objeções disponíveis na bibliografia contemporânea sobre o assunto. Uma das mais poderosas é a de que a proteção absoluta conferida aos indivíduos não nos fornece recursos para distinguir entre violações de direito triviais e violações graves. Todas são igualmente sérias:

Chamarei a classe de teorias deontológicas que parecem sofrer dessa dificuldade de teorias "Amplas, Tudo ou Nada". Tais perspectivas têm o objetivo de iluminar uma ampla faixa do terreno moral com um único princípio. Além disso, o princípio sugere de forma bastante natural que uma ação ou tem totalmente o aspecto moralmente problemático ou não o tem de modo algum. Intuitivamente, o problema é que perspectivas assim misturam casos triviais e extremos e os tratam como se fossem igualmente importantes do ponto de vista moral. Chame a isto de o problema da conflação (2013, p.103).

A ideia de que uma violação trivial e uma grave são moralmente erradas na mesma medida é difícil de aceitar, mas é um custo com o qual o defensor da tese precisa arcar. Afinal, não há como derivar dela qualquer hierarquia entre direitos. Outra forma de perceber o ponto de Sobel é por meio do contraste entre algumas ações. Imagine que uma pessoa A está com o braço posicionado de um modo que bloqueia a porta. Na primeira situação, B quer entrar e pede licença. A então levanta o braço e tudo transcorre sem problemas. Imagine agora um par de situações distintas. Na primeira, A move o braço de B sem solicitar-lhe coisa alguma. Trata-se de uma agressão leve que pode muito bem ser descrita como uma grosseria vulgar. Na segunda, A arranca o braço de B. Temos, portanto, três ações:

1) A pede licença e $B$ move o braço;

2) A move o braço de B;

3) A arranca o braço de B.

À luz do problema da conflação, as ações 2 e 3 "têm totalmente o aspecto moralmente problemático" e não há qualquer recurso teórico que nos permita dizer que 3 é pior do que 2. Para todos os efeitos, temos de nos contentar com a ideia de que 2 e 3 são igualmente más, uma vez que são totalmente más. E temos também de nos contentar, consequentemente, com a ideia de que 
não há uma gradação moral entre ambas. Intuitivamente, diríamos que 1 não tem qualquer gravidade, que 2 tem alguma e que 3 é assustadoramente grave. $\mathrm{E}$ diríamos também que, mesmo se aceitarmos que 2 e 3 fazem parte de um mesmo grupo (o grupo de ações que violam direitos), 1 e 2 estão, em algum sentido, moralmente mais próximas entre si do que 2 e 3 . A tese da autopropriedade não consegue, assim, dar conta do senso comum.

Seu defensor poderia responder que a objeção não aponta para nada de muito grave, uma vez que o diapasão moral da tese não está de todo descalibrado. Muito embora o problema da conflação mostre que ela não é capaz de diferenciar a gravidade das ações, o fato de ações triviais e graves serem tratadas com a mesma severidade indica ao menos que a tese toma como erradas as ações erradas e como corretas as ações corretas. Se a tese prescrevesse ações imorais ou proibisse ações corretas, aí sim teríamos um problema grave. Infelizmente, porém, visto de uma ótica mais prática, o problema da conflação acarreta uma consequência terrivelmente difícil de aceitar: a vida em sociedades modernas seria inviável caso a tese fosse seguida à risca. Afinal, teríamos proteção absoluta contra violações absolutamente triviais, como meros resquícios de fumaça emitidos por vizinhos ou construções

Em seu For a New Liberty: The Libertarian Manifesto (1973), Murray Rothbard parece estar disposto a pagar o preço. De maneira um tanto dramática, ele argumenta que os poluidores enviam tóxicos prejudiciais aos pulmões de vítimas inocentes e muitas vezes ignorantes a respeito das emissões. Essas emissões, pensa ele, são formas de agressão. Por essa razão, deveriam ser proibidas.

Mas se as atividades poluidoras devem ser proibidas porque violam direitos de propriedade, o que dizer de atividades barulhentas? Considere alguém que mora próximo a um estádio. A frequência de eventos é grande e o barulho costuma ter um efeito desagradável. Será que a pessoa pode impedir as atividades no estádio para preservar o conforto dos ouvidos? Por que, do ponto de vista moral, uma onda sonora é diferente de um resquício de fumaça? Uma vez que o defensor da tese da autopropriedade não dispõe de um recurso principialista para barrar contraexemplos desse tipo, eles se multiplicam. Joseph Heath descreve a vida em uma sociedade que leva a tese da autopropriedade rigorosamente a sério:

Para imaginar como seria um conjunto "completo" de direitos de propriedade, você deve conceber todos andando em bolhas de plástico grandes, opacas, a prova de som e dotadas de controle de temperatura. A ninguém é permitido a introdução de qualquer coisa na sua bolha - nenhuma luz, nenhum barulho, nenhum líquido ou gás - sem a sua permissão expressa. [...]. Como resultado, você não pode ser submetido involuntariamente a qualquer estímulo visual ou 
auditivo [e] não é obrigado a ingerir ou inalar qualquer coisa que não queira (2010, p.74).

$\mathrm{Na}$ próxima seção, apresento mais um problema associado à concepção absolutista de direitos individuais.

\section{O problema dos bens públicos}

Dadas as barreiras intransponíveis impostas pelos direitos individuais, é difícil imaginar algum empreendimento que consiga ser moralmente aceitável. Proponho agora uma pergunta econômica: será que uma sociedade de grande porte em que a proposta de Nozick é aplicada à risca se arranjaria para prover bens públicos? É uma pergunta relevante, pois, além da óbvia importância social desses bens, o defensor da tese da autopropriedade poderia dizer que esses bens básicos seriam voluntariamente fornecidos com facilidade, sem a necessidade de violar direitos. Porém, há o risco de indivíduos nozickianos caírem em problemas de ação coletiva.

Problemas de ação coletiva são situações em que as pessoas envolvidas têm um interesse coletivo em determinado resultado, mas, individualmente, ninguém tem incentivos para fazer o que é necessário para efetivá-lo. Imagine que A mora em um condomínio habitado por várias pessoas. Todos querem que haja água suficiente para os períodos de seca. Mesmo assim, A sabe que se ele abusar do consumo e os outros cooperarem, não irá faltar água. Afinal, o consumo individual não é capaz de provocar uma situação muito desastrosa. Naturalmente, há uma boa chance de as outras pessoas pensarem da mesma forma e agirem de acordo. Quando isso acontece, os incentivos individuais de cada um colidem com o interesse coletivo de ter água para os períodos de seca. Como sumariza Heath (2004), é um erro assumir que se um grupo tem um interesse coletivo em um resultado, cada indivíduo que o compõe terá um interesse particular em ajudar a efetivá-lo.

Do ponto de vista de $\mathrm{A}$, a melhor situação possível é aquela em que ele abusa da água e os outros cooperam. Infelizmente, a mesma coisa é verdadeira do ponto de vista dos outros. Assim, todos ficam em uma situação pior do que aquela em que estariam se tivessem usado menos água. Há alguns modos de resolver o problema. Estabelecer uma cota máxima por residência é uma delas, mas talvez seja uma medida drástica demais. É provável que a melhor alternativa seja a imposição de uma multa considerável sobre o que passar de uma determinada quantidade. Perante a perspectiva de sentir no bolso os custos do excesso, pensar duas vezes antes de gastar água se torna uma atitude recomendável. O que a multa essencialmente faz é oferecer um incentivo individual para o gasto responsável. Ela alinha à força os interesses individual e coletivo. 
Antes de saber se esse tipo de problema emerge com a provisão de bens públicos em uma sociedade nozickiana, é necessário saber o que eles são. Bens públicos são bens não excludentes e não rivais. Dizer que um bem é não excludente é dizer que as pessoas não podem ser impedidas de usá-lo. E dizer que não são rivais é dizer que seu uso por parte de alguém não reduz a disponibilidade para as outras pessoas. Gregory Mankiw (2010) dá o exemplo de uma sirene de tornado em uma cidade. Quando ela soa, "é impossível impedir que alguém a ouça (não é excludente). E, quando alguém recebe o benefício do sinal de perigo, isso não reduz o benefício conferido aos demais habitantes (não é rival). Há, contudo, outros exemplos menos distantes. Os benefícios de uma política econômica responsável, por exemplo, também são bens públicos. Compare os bens públicos com uma peça de roupa, que é um bem privado. Se uso uma calça, você não pode usá-la ao mesmo tempo (é excludente) e não tem os benefícios dela (é rival).

O ponto mais importante aqui é o seguinte: se, por definição, uma pessoa não pode ser excluída do usufruto dos bens públicos, ela tem incentivos para não cooperar com sua provisão. Afinal, se ela não cooperar e as outras cooperarem, ela terá acesso aos benefícios e não precisará arcar com qualquer custo. Uma vez que os incentivos são idênticos para as outras pessoas, retornamos a um problema de ação coletiva. Todos querem se beneficiar dos bens públicos, mas ninguém tem incentivos individuais para provê-lo. Tal como A e seus vizinhos ficarão sem água, as pessoas ficarão sem os bens.

Iniciei esta seção dizendo que grupos grandes não conseguiriam provê-los. Para entender a razão disso, é importante ter em mente um aspecto importante típico de grupos pequenos. Nestes, é comum haver membros que

ficariam melhor se o benefício coletivo fosse provido, mesmo que tivessem de arcar com todos os custos sozinhos, do que se o benefício não fosse provido. [...]. Assim, em um grupo muito pequeno, onde cada membro fica com uma porção substancial do ganho total simplesmente porque há poucos membros no grupo, um benefício coletivo frequentemente pode ser provido através da ação voluntária, centrada nos próprios interesses dos membros do grupo ${ }^{6}$.

Além disso, segundo Olson, em geral "a pressão social e os incentivos sociais funcionam somente em grupos de tamanho menor, [...] pequenos o bastante para haver um contato face a face com todos os demais" (1999 [1965], p.45). Isso não é uma surpresa, uma vez que o comportamento

6 Cf. OLSON, 1999 [1965], p.46. "Benefícios coletivos" e "bens públicos" são termos intercambiáveis. 0 termo mais popular, no entanto, é "bens públicos". 
individual em grupos pequenos afeta mais o grupo do que o comportamento individual em grupos grandes. O que é importante reter aqui é que grupos pequenos têm uma vantagem natural no fornecimento de bens públicos. A chance de haver indivíduos para quem os benefícios individuais de prover um bem superam os custos da provisão é grande o suficiente para tornar o fornecimento provável. Em grupos menores, portanto, a distância entre os incentivos individuais e a realização do interesse coletivo é significativamente menor, a ponto de haver uma confluência entre eles.

As coisas se complicam quando lidamos com grupos grandes. $\mathrm{O}$ primeiro problema é que quanto maior for o grupo, menor será a fração do benefício recebido por cada membro que atue pelos interesses do grupo. Assim, diminui a probabilidade de algum subgrupo ou membro individual ter os custos do fornecimento do bem público compensados pelos benefícios que retira dele (tal como os custos de diminuir o meu consumo de água não é compensado pelos benefícios dessa ação). Além disso, o custo organizacional do fornecimento de bens públicos cresce quanto maior for o grupo (1999 [1965], p.60). Por essas razões, conclui Olson logo em seguida, na ausência de coerção ou de incentivos independentes e externos, a dificuldade de prover bens públicos crescerá em proporção ao tamanho do grupo, o que pode culminar na infeliz situação de não haver sequer quantidades mínimas de bens cuja existência beneficiaria a todos ${ }^{7}$.

Olson define o termo "coerção" como uma punição que deixa o indivíduo em uma situação pior do que aquela em que ele estaria caso tivesse contribuído com os custos do bem. Já o termo "incentivo independente" é uma recompensa que deixa o indivíduo em uma situação melhor do que aquela em que ele estaria caso não tivesse contribuído (1999 [1965], p. 63). Por que isso é um problema para Nozick? Recordemos que os direitos individuais são absolutos. Assim, por um lado, é difícil pensar em uma punição que não viole os direitos de um indivíduo recalcitrante. $\mathrm{O}$ modo mais óbvio de punir o indivíduo é leva-lo para a cadeia caso ele se recuse a pagar os tributos necessários para o fornecimento do bem ou multá-lo pela mesma razão. Mas ao tentar resolver o problema dessa forma, o estado viola direitos. Indivíduos nozickianos têm direitos absolutos de propriedade sobre si e sobre seus haveres, de modo que tanto a violação de sua integridade física quanto a

${ }^{7}$ Em uma formulação mais precisa, Olson diz que: "[o] indivíduo membro da grande organização típica está em uma posição análoga à da empresa em um mercado perfeitamente competitivo, ou à do contribuinte em um estado: seus esforços individuais não terão um efeito sensível sobre a situação de sua organização, e ele poderá desfrutar de quaisquer vantagens obtidas pelos outros quer tenha ou não colaborado com o grupo" (1999 [1965], p.28). 
retirada compulsória de sua propriedade são vedadas. Logo, uma entidade central como o estado não poderia fazer o que tipicamente faz para prover esses bens. E mesmo assumindo a premissa de que o bem é fornecido, é pouco provável que haja uma maneira moralmente legítima de contar com os recursos necessários para mantê-lo em funcionamento. Em suma, direitos absolutos de propriedade acabam por fechar as portas para uma das soluções mais óbvias para a resolução de problemas de ação coletiva. Diferentemente do que ocorre em exemplos comuns, o alinhamento forçado entre os interesses individual e coletivo seria proibido.

Richard Arneson (2011) recorre a um exemplo drástico para dar contornos morais ao problema. Ele convida o leitor a se imaginar com outras pessoas em um fosso. Dentro dele, um animal feroz se apresenta como uma ameaça. Caso todos lutem, a besta pode ser derrotada. Uma estratégia é traçada. Porém, embora alguns decidam lutar, outros optam por nada fazer. Assumindo que a besta é derrotada, os que optam por não lutar se beneficiam da luta dos outros sem fazer qualquer esforço. A derrota do animal é um exemplo extremo de bem público. Os que lutam não podem excluir os que não lutam dos benefícios da derrota do animal, e o usufruto desse resultado por um indivíduo não diminui o que o outro terá. Os benefícios são, portanto, não excludentes e não rivais. Porém, como aponta Arneson, os que fogem da luta podem simplesmente recorrer à tese da autopropriedade para dizer que ninguém pode forçá-los a contribuir com a provisão desse valioso bem público. Por isso, "[o] direito à autopropriedade inchi o direito moral de ser um carona" (2011, p. 25, grifo meu) $)^{8}$.

Além disso, por que deveríamos supor que os indivíduos contribuiriam caso lhes fosse oferecido um incentivo que os colocasse meramente em uma situação melhor do que a alternativa na qual não contribuem? Uma vez que eles sabem que estão protegidos contra a coerção externa, o preço de sua contribuição tenderá a subir. Assim, indivíduos recalcitrantes ficam em uma condição bastante confortável para pedir um incentivo maior.

Parece razoável concluir que uma sociedade de indivíduos autoproprietários teria grandes dificuldades para fornecer bens públicos. Seria muito difícil coibir o comportamento do carona que, sem contribuir, quer se beneficiar do que é fornecido pelos outros. A conjunção entre autopropriedade, grupos grandes e problemas de ação coletiva é

8 O termo "carona" é uma tradução do inglês free rider. Designa o indivíduo que se beneficia de um bem sem ter contribuído para fornecê-lo. Ele "pega carona" no benefício dos bens que os outros fornecem. 
particularmente infeliz. É como se o síndico do condomínio nada pudesse fazer para reduzir o consumo de água. Nozick certamente não se sentiria consolado ao saber que bens públicos provavelmente seriam fornecidos por indivíduos autoproprietários apenas em grupos pequenos.

\section{Transpor e compensar: uma possível saída}

Os problemas descritos acima sugerem que a forma mais adequada de respeitar a autopropriedade é viver em sociedades nas quais o isolamento individual absoluto é o costume comum. Mas em que sentido poderíamos dizer que isso é uma sociedade? Ironicamente, a ideia de separação das pessoas acaba por se tornar literal demais. É precisamente nessa altura que Nozick recua de sua concepção absolutista, pois uma teoria que sacrifica quase toda a liberdade de ação no altar do respeito aos direitos individuais não é muito atraente.

Nozick agora propõe que é permissível transpor as fronteiras estabelecidas pelos direitos individuais desde que uma compensação seja paga a quem teve os direitos transpostos. A ideia aqui não é a de compensar por uma violação prévia de algum direito; é a de que é permissível transpor (repare que até o termo muda) um direito desde que se pague uma compensação integral. Agora, caso haja compensação, o direito sequer é violado. Mas como saber se alguém foi efetivamente compensado? Nozick inicialmente sugere que "[a]lgo compensa integralmente alguém por uma perda se, e só se, não a deixa pior do que de contrário teria ficado" (2009 [1974, p.90). Tal como em Olson, estar melhor ou pior aqui é especificado relativamente à posição em uma curva de indiferença. Logo depois, contudo, Nozick reconhece que isso pode não ser justo, pois força a quem tem sua fronteira transposta a aceitar "o ponto de contrato mais favorável ao comprador" [1974], p.97-8, grifo do autor). Para ilustrar, é como se um vendedor fosse forçado a aceitar o preço mais baixo por seu produto. Por isso, os indivíduos aos quais a compensações são dadas devem receber o valor que seria estabelecido caso os preços das transposições fossem formados em um ambiente de mercado. A estratégia de Nozick, em suma, é abandonar a ideia de que os direitos individuais funcionam como barreiras e encará-los como parâmetros que estabelecem uma referência para as compensações.

A intenção de Nozick ao permitir transposições devidamente compensadas é tornar sua teoria compatível com um grau razoável de liberdade de ação e com o desenvolvimento econômico. Como ressaltou Zwolinski, muitos teóricos "se preocupam com o fato de que o absolutismo desses direitos os tornam incapazes de se adequar aos tipos de trade-offs que parecem ser necessários em um mundo moralmente complicado" (2014, p.10). 
Ao rejeitar o absolutismo, Nozick consegue acomodar melhor esses trade-offs. Mas será que ele não acaba por permitir demais? Permitir danos triviais mediante compensação soa plausível. A plausibilidade diminui, contudo, quando o direito a ser transposto é mais importante. Dada uma compensação adequada, será que A pode, por exemplo, arrancar o braço de $\mathrm{B}$, que insiste em mantê-lo na porta?

O problema da conflação mostra o quão irrazoável é considerar intransponíveis todos os direitos. A resposta a ele, porém, acarreta uma consequência bizarra: qualquer fronteira é, em princípio, passível de transposição. Começamos com uma teoria segundo a qual os direitos são absolutos. Agora, eles não são mais do que indicativos de preços. Nozick, porém, adota uma saída ainda mais engenhosa para contornar o novo problema. E se as transposições que intuitivamente consideramos mais graves forem, por algum motivo não ad hoc, impermissíveis?

Ele recorre a algo que podemos chamar de "argumento do medo":

Há coisas que recearíamos mesmo sabendo que seríamos compensados integralmente se nos acontecessem ou se no-las fizessem. Para evitar tal apreensão e medo gerais, estes atos são proibidos e puníveis. [...]. Nem todo o tipo de transposição de fronteira cria esse medo. [...]. Isto dá-nos uma dimensão para distinguir entre os delitos privados e delitos com uma componente pública. Os delitos privados são aqueles em que só é preciso compensar a parte lesada; as pessoas que sabem que serão compensadas integralmente não o temem. Os delitos públicos são aqueles de que as pessoas têm medo, ainda que saibam que serão compensadas integralmente se os delitos ocorrerem e quando ocorrerem (2009 [1974], p. 100-101, grifo do autor).

É claro que para isso ser um problema, temos de aceitar que provocar medo é uma transposição - o que podemos tomar como uma sugestão plausível. Sendo assim, se vivemos em uma sociedade na qual qualquer pessoa pode cometer um delito público, é de se esperar que todos vivam em constante estado de medo, o que multiplica as transposições e consequentemente as reivindicações de compensação. Nozick, assim, espera que o medo causado pelos delitos públicos seja grande a ponto de sua compensação ser inviável. E perante essa inviabilidade prática, proibem-se os delitos públicos. Repare que Nozick consegue oferecer um argumento para permitir transposições triviais (quem ficaria com medo da perspectiva de ouvir alguns sons de martelo vindos de uma fábrica?) e ao mesmo tempo impedir transposições mais graves sem fažer uma distinção principialista entre transposiçoes triviais e graves. Para todos os efeitos, grave é aquilo que causa medo às pessoas, seja lá o que isso for. Sua perspectiva da compensação parece impedir precisamente os mesmos atos que seriam impedidos por um argumento principialista bem-sucedido. 
O problema da conflação e o problema dos bens públicos mostram que a autopropriedade dificulta o desenvolvimento social e econômico. Contudo, ao permitir transposições de fronteira mediante compensação, Nozick parece conceder mais do que deveria. Afinal, o que se quer é permitir transposições leves, mas indispensáveis ao desenvolvimento, e não transposições graves. Habilmente, ele sugere que a perspectiva de viver em uma sociedade que permite certas transposições é amedrontadora. Uma vez que compensar por esse medo difuso é uma tarefa inviável, certas transposições não devem ser permitidas. Assim, ele retém as transposições que queremos reter e rejeita as que queremos rejeitar sem distinguir de forma direta entre transposições triviais e graves.

\section{Porque a saída não é bem-sucedida}

Nesta seção, mostro que tanto a posição atenuada de Nozick quanto um eventual retorno à concepção absolutista fracassam. E agora isso não se deve à mera implausibilidade das implicações da estrutura de direitos nozickiana, mas a tensões internas. Com isso quero dizer o seguinte: as objeções levantadas contra Nozick nesta seção se assentam em aspectos aceitos por ele em algum momento e suscitam um conflito com outros aspectos também aceitos por ele. Trata-se de usar Nozick para atacar Nozick. ${ }^{9}$ Veremos, assim, que a versão atenuada acarreta a existência de direitos positivos, o que não é desejável a um libertário como Nozick, e que ela é incompatível com a perspectiva nozickiana de vida com sentido. Inspirado nessa estratégia de ataque, irei sugerir que até mesmo o retorno à concepção absolutista, por definição compatível com a estrutura de direitos negativos, é provavelmenente incompatível com a mesma perspectiva de vida com sentido. Minha ambição é mostrar que a teoria de Nozick padece desse tipo de problema sob qualquer um dos dois dois ângulos disponíveis.

O leitor perceberá que a maior parte das deficiências apontadas aqui é gerada por um aspecto do último passo da reformulação da teoria. Como vimos, Nozick não faz uma distinção principialista entre transposições triviais

\footnotetext{
${ }^{9} \mathrm{O}$ leitor pode estar desconfiado de que o problema da conflação foi formulado como uma objeção do mesmo tipo. Não é o caso. Ali, realmente se partiu de algo aceito por Nozick - 0 aspecto "tudo ou nada" da teoria. Mas o ponto de chegada (os problemas práticos que o aceite da teoria implica) não conflitou com nada previamente aceito. Tratou-se simplesmente de mostrar uma implicação que é implausivel em um sentido comum, tal como nos casos em que simplesmente dizemos algo como o seguinte: "se sua teoria implica X, ela é implausível". A extravagância de X já é suficiente para oferecer a objeção. Com isso não quero dizer que não seja possível apresentar uma tensão entre o problema da conflação e algum aspecto previamente aceito por Nozick.
} 
e graves. A vantagem de não fazê-la é justamente escapar da tarefa de estabelecer fronteiras precisas, o que o colocaria na desconfortável situação de ter de justificá-las. Em outros casos, porém, a ausência de distinções similares evidencia tensões internas de difícil solução.

Eis como Sobel introduz o primeiro ponto:

\begin{abstract}
[S] uponha que os outros tenham o direito de não me ajudar caso eu caia em um poço. Eles deveriam me dar uma compensação pelo medo que sinto de morrer sem ajuda num sistema que permite tal coisa? [...]. Se o medo racional gerado por um sistema de direitos pode, por si próprio, determinar que uma fronteira foi transposta, então um sistema de direitos que gera um medo racional de não ser ajudado também exige compensação (2012, p.45).
\end{abstract}

A dificuldade de Nozick aqui, portanto, é a seguinte: aceitamos que a transposição seguida de compensação é moralmente permissível e que o medo de ser submetido a certas ações moralmente permissíveis exige compensação. Aceitamos também que certas transposições causam muito medo, o que inviabiliza sua compensação e leva à sua proibição. Um dos pontos mais importantes dos compromissos filosóficos de Nozick, contudo, é o de que não ajudar uma pessoa que cai em um poço é moralmente permissível. Afinal, ao não fazê-lo, nenhum direito negativo é violado. Mas é razoável pensar que se a sociedade permitir tal coisa, as pessoas também sentirão muito medo. Viver em uma sociedade na qual não se pode esperar por ajuda em situações desesperadoras pode causar um medo grande demais para ser compensado. Se isso for o caso, a solução nozickiana, portanto, seria tornar essas omissões impermissíveis.

Mas se não podemos ser omissos, parece que temos obrigações para com os outros. Trata-se de uma má notícia para um defensor da ideia de que há apenas direitos negativos. Nozick não pode simplesmente dizer que todos os medos são iguais, mas alguns medos são mais iguais que os outros. Em particular, ele não pode distinguir entre medos causados por ações e medos causados por omissões, pois o que agora desempenha o papel de permitir ou proibir qualquer conduta é apenas o medo. Tal como ele não tem recursos principialistas para distinguir entre transposições triviais e graves, ele não tem recursos para tratar de maneira distinta a origem dos diferentes medos. Infelizmente, o medo não discrimina entre direitos negativos e direitos positivos.

Mas o que aconteceria se as pessoas sentissem medo de adoecer sem ter um sistema de saúde gratuito? E se sentissem medo de não ter atendimento escolar? Se aceitarmos que esses medos são grandes demais para serem compensados, um sistema de saúde teria de ser fornecido, tal como um sistema de educação público. Sorrateiramente, direitos positivos entram em cena por 
meio de recursos teóricos avançados pelo próprio Nozick. Ao não fazer uma distinção direta entre transposições triviais e graves, Nozick apresenta o argumento do medo como um modo não ad hoc de separar as transposições aceitáveis daquelas que não são aceitáveis. Porém, uma vez que não é possível distinguir entre medos que contam e medos que não contam, a estrutura de direitos nozickiana se torna demasiadamente inflacionada para os padrões de uma teoria libertária.

Outro ponto fraco na posição de Nozick é o fato de a transposição seguida de compensação permitir potenciais interrupções nos planos que as pessoas fazem para si mesmas (SOBEL, 2012, p.47). Mas será que isso é um problema real? Considere uma pessoa para quem a vida boa é a vida no silêncio campestre. Presumivelmente, podemos transpor-lhe as fronterias e oferecer uma compensação caso decidamos construir uma fábrica nas proximidades de sua estância. Afinal, o incômodo causado a essa pessoa é pequeno demais e não é de se esperar que ela sinta medo. À primeira vista, poderíamos dizer que algo tão insiginificante não consegue, em qualquer sentido interessante, prejudicar os planos de quem quer que seja. Sobel, portanto, pecaria pelo exagero nesta objeção.

Tal resposta, contudo, enfrenta uma dificuldade similar àquela que vimos logo acima. Mais uma vez, Nozick não oferece uma distinção qualitativa entre os planos que as pessoas fazem para a própria vida. E uma vez que eles, de forma não qualificada, fazem parte de sua concepção de vida com sentido presente na teoria, interrupções em quaisquer planos são uma forma de desrespeitar a "capacidade de regular e orientar a sua vida de acordo com uma concepção geral que [o indivíduo] escolhe aceitar" (2009 [1974], p.102). Logo, se a concepção geral aceita pela pessoa envolve apenas uma vida protegida dos barulhos incômodos causados por fábricas, desrespeitamos sua capacidade de regular e orientar a própria vida ao construir a fábrica. $\mathrm{Na}$ ausência de uma distinção entre formas de moldar a própria vida, até mesmo transposições triviais podem ser uma grave ameaça ao que Nozick via de tão especial em uma pessoa. Nozick, em suma, não pode responder que alguns planos são mais iguais que os outros. Por assim dizer, a porta que a permissibilidade das transposições abre é fechada por certos planos particularmente exigentes.

Quando propõe o argumento do medo, Nozick inadvertidamente abre sua teoria aos direitos positivos. Abandonar o argumento do medo, contudo, parece ser uma opção custosa, pois deixaria a teoria ainda no estágio absolutista. Por outro lado, manter uma concepção ampla de vida com sentido permite que mesmo transposições inocentes violem algo de central importância para Nozick. Vemos, portanto, que a perpectiva atenuada da teoria abriga sérias tensões internas. E tal como ele não tinha recursos para 
oferecer uma distinção direta entre transposições triviais e transposições graves, ele não parece tê-los para distinguir entre diferentes medos e diferentes planos pessoais. E mesmo se ele oferecesse um modo indireto de resolver o problema, a solução provavelmente acarretaria ainda mais problemas.

E se defendêssemos um retorno ao estágio absolutista? Por mais que a posição tal como inicialmente formulada enfrente algumas dificuldades, suas componentes não parecem entrar em conflito. Talvez a melhor opção seja o retorno a uma posição extremamente austera, mas internamente harmônica. Finalizo este artigo defendendo que até mesmo a versão absolutista da teoria enfrenta ao menos uma grave tensão interna.

Wolff (1991, p.31) observa que se as pessoas tiverem apenas direitos negativos, não existe garantia de que elas terão condições de levar uma vida que vale a pena ser vivida. Afinal, uma sociedade de autoproprietários plenos é, do ponto de vista moral, compatível com quantidades enormes de pobreza desde, é claro, que ela não seja resultado de violação de direitos negativos. Mas se este for realmente o caso o caso, a vigência de direitos negativos absolutos pode não ser o arranjo adequado para que a generalidade dos indivíduos formule planos diversos, recompensadores e de longo prazo - para que, em outras palavras, os indivíduos tenham uma vida com sentido. Logo, se calhar de o estado mínimo nozickiano produzir, em virtude de não haver quaisquer direitos positivos, uma grande quantidade de pessoas muito pobres, surge um conflito entre o ideal de indivíduo capaz de moldar a própria vida e o tipo de sociedade que emerge quando há apenas direitos negativos. $\mathrm{O}$ apelo filosófico (e retórico) de um indivíduo autônomo "capaz de formular planos de longo prazo para a sua vida, de considerar e decidir com base em princípios abstratos" parece depender ao menos de um background material próspero o suficiente para permitir a ele tais coisas. E é uma questão empírica saber se uma sociedade de indivíduos autoproprietários dotados de direitos absolutos de não intervenção forneceria esse background (a discussão sobre os bens públicos indica que não). Nozick não pode, portanto, usar as ideias de direitos unicamente negativos, autopropriedade e separação das pessoas para motivar uma concepção substancial de vida com sentido, pois esta pode acabar por ser enfraquecida pela vigência das primeiras. Por essa razão, é razoável defender que a manutenção da estrutura de direitos aceita pela teoria exige um enfraquecimento da concepção de vida com sentido. E não é claro que o resultado desse enfraquecimento seja atraente. Uma vida com sentido pode se tornar algo insubstancial demais para ser desejada.

Repare que a força do argumento acima não depende de uma eventual distinção entre planos aparentemente irrelevantes (como o de não ser incomodado por qualquer barulho) e planos importantes, o que torna esta 
objeção potencialmente mais poderosa que as anteriores. Afinal, a vigência de direitos unicamente negativos afeta especialmente os planos mais importantes - dedicar-se à matemática ou à culinária, por exemplo, exige um background adequado, ao passo que o isolamento é suficiente para viver sob o silêncio. Em outras palavras, mesmo uma concepção menos permissiva e mais plausível de vida com sentido provavelmente entraria em conflito com os direitos nozickianos.

Talvez a perspectiva nozickiana de vida com sentido seja, na verdade, satisfeita por propostas como a de Scheffler, para quem "[c]ada pessoa tem um direito natural a uma quantia suficiente de todo bem distributivo cuja posse é condição necessária para se ter uma chance razoável de viver uma vida decente e satisfatória" (1982, p.153). Se isso for mesmo o caso, manter a concepção nozickiana de vida com sentido significa o abandono da exclusividade dos direitos negativos. Afinal, é razoável pensar que apenas indivíduos dotados de condições materiais satisfatórias estão em condição de decidir com base em princípios abstratos, pois não são escravos do reino da necessidade. Por outro lado, manter a exclusividade dos direitos negativos significa o abandono da concepção nozickiana de vida com sentido, que é atrante precisamente por ser robusta. Em qualquer caso, a situação que emerge é particularmente desconfortável, pois ou bem uma concepção atraente é sacrificada em prol da estrutura de direitos absolutos característica do libertarismo ou bem essa estrutura não é desejável do ponto de vista de indivíduos reais e o libertarismo nozickiano também não o é. Há razões, portanto, para pensar que mesmo a versão mais básica de libertarismo sofre de tensões internas de difícil solução.

Se o conteúdo apresentado aqui apontar para a direção correta, é possível articular dois níveis de objeções a Nozick: o primeiro e mais comum diz respeito a certas implicações implausíveis da teoria, sumarizadas no primeiro comentário de Joseph Heath. O segundo mostra as tensões que surgem no interior da própria teoria. A partir das observações de Sobel, mostrei que isso ocorre na versão reformulada da teoria. Mais ao fim, sugeri que isso também ocorre na versão absolutista e que a tensão observada neste contexto é especialmente grave, pois indica que estamos diante de uma teoria que, em sua formulação mais óbvia, talvez não ofereça à generalidade das pessoas uma vida com sentido em virtude do rigor dos direitos que ela própria aceita.

\section{Conclusão}

Após apresentar a estrutura dos direitos individuais nozickianos e seus alicerces, ofereci razões tanto filosóficas quanto práticas para pensar que todo o conjunto é controverso. A principal razão filosófica foi o problema da 
conflação. No âmbito mais prático, recorri a um clássico das ciências sociais para defender que sociedades nozickianas de grande porte teriam problemas econômicos severos. Afinal, a vigência da autopropriedade protege maus incentivos. A tentativa de Nozick de reformular a tese da autopropriedade para dar conta desses fatos falha ora porque permite a introdução de direitos positivos ora porque entra em conflito com a perspectiva nozickiana de vida com sentido. $O$ retorno à posição absolutista, por sua vez, além de não resolver as falhas apontadas no início, corre o sério risco de também ser enredado por tensões internas.

\section{Referências}

ARNESON, R. "Side Constraints, Lockean Individual Rights, and the Moral Basis of Libertarianism". In: BADER, R.; MEADOWCROFT, J. (Org.). The Cambridge Companion to Nozick's Anarchy, State, and Utopia. Cambridge:

Cambridge University Press, 2011. p.15-37.

COHEN, G. A. Self ownership freedom and equality. Cambridge: Cambridge University Press, 1995.

HEATH, J. Economics Without Illusion: Debunking the Myths of Modern Capitalism. Toronto: Crown Business, 2010.

. Nation of Rebels: Why Counterculture Became Consumer Culture. Nova York:

HarperCollins, 2004.

KANT, I. Lectures on Ethics. Cambridge: Cambridge University Press, 1997.

LOCKE, J. Dois Tratados Sobre o Governo. Trad. Julio Fischer. 2. ed. São Paulo: Martins Fontes, 2001.

MACK, E. "Robert Nozick's Political Philosophy". In: The Stanford Encyclopedia of Philosophy (Summer 2015 Edition), Edward N. Zalta (ed.). Disponível em: <https://plato.stanford.edu/archives/sum2015/entries/nozick-political/>.

MANKIW, N. G. Introdução à Economia. Trad. Allan Vidigal Hastings e Elisete Paes e Lima. São Paulo: Cengage Learning, 2010.

MILL, J. S. On Liberty and Other Essays. Oxford: Oxford University Press, 2008.

NOZICK, R. Anarquia, Estado e Utopia. Trad. Vitor Guerreiro. Lisboa: Edições 70, 2009.

OLSON, M. A Lógica da Ação Coletiva. Trad. Fabio Fernandez. São Paulo: Edusp, 1999. 
ROTHBARD, M. For a New Liberty: The Libertarian Manifesto. Nova York: Collier Books, 1973.

SANDEL, M. Justice: What's The Right Thing to Do? Nova York: Farrar, Straus and Giroux, 2009.

SCHEFFLER, S. "Natural Rights, Equality, and the Minimal State”. In:

PAUL, J. (Org.). Reading Nozick. Oxford: Blackwell, 1982. p.148-68.

SOBEL, D. "Backing Away from Libertarian Self-Ownership". In: Ethics, v.123, n.1, p.32-60, 2012.

. Self-Ownership and the Conflation Problem. In: TIMMONS, M.

(Org.). Oxford Studies in Normative Ethics. Oxford: Oxford University Press, 2013, p.98-122.

VALLENTYNE, E.; STEINER, H.; OTSUKA, M. "Why Left-Libertarianism Is Not Incoherent, Indeterminate, or Irrelevant": A Reply to Fried”. In:

Philosophy \& Public Affairs, v.33, n.2, p.201-215, 2005.

VALLENTYNE, P. “Left Libertarianism”. In: CHRISTIANO, T.;

CHRISTMAN, J. (Org.). Contemporary Debates in Political Philosophy. Oxford:

Blackwell, 2009, p.135-151.

WOLFF, J. Robert Nozick: Property, Justice and the Minimal State. Stanford:

Stanford University Press, 1991.

ZWOLLINSKI, M. “Libertarianism and Pollution”. In: Philosophy \& Public Policy Quarterly, v.32, n.3/4, p.9-21, 2014.

E-mail: aluizio.couto2112@gmail.com

Recebido: 05/2017

Aprovado: 09/2017 